\title{
K-ras point mutations in routinely processed tissues: Non-radioactive screening by single strand conformational polymorphism analysis
}

\author{
S H Korn, P T M Moerkerk, A F P M de Goeij
}

\begin{abstract}
Aims-To develop a non-radioactive method to screen routinely fixed, paraffin wax embedded specimens for the occurrence of point mutations; to evaluate the single strand conformational polymorphism (SSCP) analysis technique for the detection of $\mathrm{K}$-ras point mutations as a result of electrophoretic mobility shifts.

Methods-DNA was extracted from archival specimens of colon cancer and from established colon cancer cell lines with known point mutations. A K-ras gene fragment containing codons 12 and 13 of exon 1 was amplified with the polymerase chain reaction (PCR). Denatured DNA fragments were run on $10 \%$ polyacrylamide gels under non-denaturing conditions. After electrophoresis DNA was blotted and the single stranded DNA was detected using a digoxigenin labelled ras probe. The nature of the detected point mutations was identified and confirmed by sequencing and hybridisation with oligonucleotides using ${ }^{32} \mathbf{P}$ labelling. Results-Wild type and aberrant alleles were detected caused by mobility shifts after electrophoresis of the PCR products. Commonly occurring mutations in the K-ras gene-in the first two positions of codon 12-could easily be detected in DNA from archival paraffin wax embedded colon cancer tissue. In all the colon tumour samples studied wild type gene alleles were also found, presumably derived from normal cells in the specimen.

Conclusions-The SSCP method permits rapid non-radioactive screening of adenomas or carcinomas for the occurrence of point mutations in the $K$-ras gene. But if a mutation is detected by an electrophoretic mobility shift, its identification requires confirmation by sequencing or oligonucleotide hybridisation.
\end{abstract}

Department of Pathology, University of Limburg Academic Hospital, PO Box $5800,6202 \mathrm{AZ}$ Maastricht, The Netherlands $S$ H Korn

P T M Moerkerk

A F P M de Goeij

Correspondence to:

Dr A F P M de Goeij

Accepted for publication

9 February 1993
$(\mathcal{C}$ Clin Pathol 1993;46:621-623)

Activation of K-ras oncogenes is related to the pathogenesis of various human tumours. The incidence of ras gene mutations in adenomas and carcinomas of the human colon is about $50 \%$. Evidence from the studies of Vogelstein et al points towards a role of ras oncogene activation in the early stages of colon cancer development. ${ }^{1}$ Point mutations which lead to ras activation were confined to the codons 12, 13, and 61 of the gene. Point mutations in codon 12 are commonly seen. ${ }^{2}$ We developed a non-isotopic method to detect point mutations in the $\mathrm{K}$-ras gene of human colon tumour cells and formalin fixed, paraffin wax embedded tissue. To this end the single strand conformation polymorphism (SSCP) analysis technique was applied ${ }^{3}$ and a digoxigenin labelled probe was used to detect the gene fragment after amplification with the polymerase chain reaction (PCR). The screening method was tested on four colon carcinoma cell lines with known single point mutations in codon 12 of the K-ras gene: CaCo2 (GGT), SW1398 (GGT + TGT), SW1116 (GCT), and SW620 (GTT). Furthermore, several colon tumour samples were analysed using routinely formalin fixed and paraffin wax embedded specimens.

\section{Methods}

Surgical colon tumour tissue was fixed with $10 \%$ formalin, embedded in paraffin wax, and stored for 10-15 years. Sections, mounted on untreated slides were dewaxed. Guided by a parallel section stained with haematoxylin and eosin, the tumour tissue was scraped off and dried. The tissue was incubated overnight with proteinase $\mathrm{K}$ (200 $\mu \mathrm{g} / \mathrm{ml} 50 \mathrm{mM}$ TRIS, $\mathrm{pH} 8 \cdot 5,1 \mathrm{mM}$ EDTA and $0.5 \%$ Tween 20 ) at $55^{\circ} \mathrm{C}$. After heating at $100^{\circ} \mathrm{C}$ for 10 minutes, debris was removed by centrifugation and the supernatant fluid stored at $4^{\circ} \mathrm{C}$ until PCR.

The first exon of the K-ras gene, which includes codons 12 and 13, was amplified with the PCR in 15 cycles with a primer set to obtain a 280 base pair fragment, followed by 25 cycles with a set of inserted primers. This latter set of primers [sense sequence 5' AAA ATG ACT GAA TAT AAA CTT GTG G 3', antisense sequence 5' CTC TAT TGT TGG ATC ATA TTC GTC 3'] resulted in PCR products with a length of 114 base pairs. ${ }^{4}$ The conditions of PCR were: denaturation for 3 minutes at $95^{\circ} \mathrm{C} ; 25$ cycles of 1 minute at $92^{\circ} \mathrm{C}, 2$ minutes at $62^{\circ} \mathrm{C}, 3 \mathrm{~min}$ utes at $72^{\circ} \mathrm{C}$; followed by 10 minutes at $72^{\circ} \mathrm{C}$.

These PCR products were loaded on a non-denaturating $10 \%$ polyacrylamide gel containing $10 \%$ glycerol. $^{3}$ DNA $(0.5 \mathrm{ng})$ dissolved in a solution containing $95 \%$ formamide, $20 \mathrm{mM}$ EDTA, $0.05 \%$ bromophenol blue and $0.05 \%$ xylene cyanol was heated at $100^{\circ} \mathrm{C}$ for 10 minutes, then 


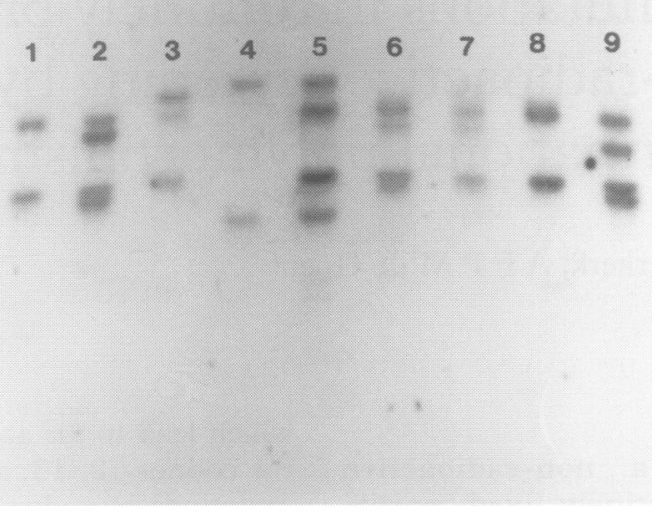

PCR-SSCP analysis of point mutations in exon 1 of the $K$-ras gene. DNA from established colon tumour cell lines with different known mutations in codon 12 showed mobility shifts. Lane 1 wild type GGT (CaCo2); lane 2 TGT (SW 1398); lane 3 GCT (SW 1116); lane 4 GTT (SW 620). In colon tumours could be identified: lane 5 GTT and wild type GGT in tumour 1 ; lane 6 TGT and wild type in tumour 2; lane 7 TGT and wild type in tumour 3; lane 8 only wild type in tumour 4; lane 9 AGT and wild type in tumour 5. All point mutations were confirmed with allele specific oligonucleotide hybridisation and sequencing.

immediately chilled on ice and applied to the gel. Electrophoresis was performed at 1000 volts for 16 hours at room temperature in a buffer containing $90 \mathrm{mM}$ TRIS-borate, $\mathrm{pH}$ 8.0 , and $2.0 \mathrm{mM}$ EDTA, using a $50 \mathrm{~cm}$ slab gel in a Gibco-BRL model S2 electrophoresis apparatus. The DNA was blotted on to Nytran membrane in a buffer containing $225 \mathrm{mM}$ TRIS-borate, $\mathrm{pH} 8.0$, and $5.0 \mathrm{mM}$ EDTA at 0.9 A for 30 minutes. DNA was crosslinked to the membrane by exposure to ultraviolet radiation (three minutes at 254 $\mathrm{nm})$.

For a non-radioactive detection system we used a modification of the Digoxigenin Luminescent Detection Method from Boehringer Mannheim, Germany. In brief: the blot was prehybridised at $52^{\circ} \mathrm{C}$ in a buffer containing $40 \%$ formamide, $5 \times$ SSC (saline sodium citrate), $2 \%$ blocking reagent, $0.1 \% \mathrm{~N}$ lauroylsarcosine, $0.02 \%$ sodium dodecyl sulphate (SDS), and $0.1 \mathrm{mg} / \mathrm{ml}$ salmon sperm DNA. Hybridisation was done at $42^{\circ} \mathrm{C}$ for at least 6 hours with a denaturated, digoxigenin labelled DNA probe for K-ras. The 114 base pair probe was labelled with digoxigenin-conjugated dUTP using the PCR. After hybridisation the membrane was washed at $63^{\circ} \mathrm{C}$ with $2 \times$ SSC, $0.1 \%$ SDS (5 minutes) and $0.1 \times$ SSC, $0 \cdot 1 \%$ SDS (20 minutes). The single stranded ras gene fragments were detected with chemiluminescence using alkaline phosphatase and AMPPD as the substrate. Nondenatured, double stranded DNA fragments were not detected with this technique.

The nature of the point mutations in the DNA from the established cell lines used in this study was identified by allele specific oligonucleotide hybridisation and by sequence analysis. Allele specific oligonucleotide hybridisation was carried out as described by Verlaan-de Vries et al, ${ }^{5}$ using probes $5^{\prime}$ 'end labelled with ${ }^{32} \mathrm{P}$. Sequence analysis was done using the dsDNA Cycle Sequencing System from BRL Life Technologies, Inc (Breda, The Netherlands) according to the method of Murray. ${ }^{6}$

\section{Results}

Results of the SSCP analysis of point mutations in cell lines and colon tumour samples are shown in the figure. The nature of the detected mutations was revealed with radioactive sequencing and with allele specific oligohybridisation (data not shown) (figure). The alleles with codon 12 wild type GGT could be observed as two bands on the gel in lane 1 and in all tumour samples in lanes 5-9. Substitutions in the first position of codon 12 were identified as TGT represented by two extra bands in lanes 2,6 , and 7 , and the AGT mutation was seen in lane 9 . Substitutions in the second base of the codon were detected as GCT, which was visualised in lane 3, and as GTT in lanes 4 and 5. The results show that the most frequently occurring point mutations in the $\mathrm{K}$-ras gene-in the first two positions of codon 12-can be detected with this technique. In all colon tumour samples studied wild type gene alleles occurred in addition to mutated alleles. These are presumably derived from normal cells in the specimen.

\section{Discussion}

SSCP analysis alone is not sufficient to establish the nature of the (point) mutation, not even when samples with known point mutations are run in parallel lanes on the gel. Therefore, radioactive sequencing and hybridisation with oligonucleotides were used to identify the mutations and seemed to confirm the SSCP results. It cannot be concluded from this study, however, that all point mutations occurring in the K-ras gene fragment can be detected using SSCP analysis, because it is not known whether each mutation results in an electrophoretic mobility shift.

The question arises as to whether this SSCP technique has advantages over other non-radioactive methods for screening paraffin wax embedded tissue samples for point mutations. The SSCP technique was not compared experimentally with non-radioactive methods, but it can be argued that its sensitivity and probably its specificity are significantly greater. A modification of the SSCP method described would be to omit the hybridisation step. This means using PCR with biotinylated or digoxigenin labelled primers, followed by electrophoresis, blotting, and visualisation with avidin or anti-digoxigenin respectively. We assume, however, a lower sensitivity due to less efficient amplification in the PCR step, caused by the modified primers, and in the detection step on the blot.

Non-radioactive sequencing could be a good alternative. It is not clear, however, whether its sensitivity is sufficient to detect 
minor proportions of aberrant sequences. We also do not expect significant gains in terms of speed and effort for this technique.

Another method would be allele specific oligonucleotide hybridisation but this approach has two main disadavantages. Firstly, because of the small size of the oligonucleotides, the introduction of only a few nucleotides per probe tagged with biotin or digoxigenin will decrease effective hybridisation and consequently the specificity of the method. Secondly, for every point mutation to be studied a specifically labelled probe has to be applied and optimal hybridisation conditions have to be established.

Another approach could be the performance of PCR with primers with mismatched 3' residues (ARMS), which results in amplification of only the mutated DNA fragments. ${ }^{7}$ This technique might be very useful for the detection of very small numbers of genes with known point mutations in the presence of large amounts of wild type alleles. We have no experience of the latter method, but we feel that adequate results critically depend on the experimental conditions of the PCR and the quality of the DNA, which is certainly not optimal for archival, paraffin wax embedded material.

The use and detection of the 114 base pair probe, labelled with digoxigenin-dUTP used in this study, is apparently sensitive enough to detect the common mutations in K-ras genes from cell lines and paraffin wax embedded tumour specimens. In contrast to oligonucleotide hybridisation and the PCR with mismatch 3' nucleotide primers, the SSCP method has the potential to reveal other (point) mutations than would be expected in the amplified gene fragment. On the other hand, a low proportion of point mutations in a sample or mutations that do not result in a mobility shift will not be detected using this technique.

We conclude that this non-radioactive method may be valuable for the screening of premalignant and malignant tissues or cells for the occurrence of K-ras point mutations. It has the advantages of sensitivity, speed, and applicability in the routine diagnostic pathology laboratory. DNA extracted from routinely fixed tissue can also be used for electrophoretic analysis. Application of adequate control samples with known mutations can give an initial indication of the genetic aberration. When a mobility shift is detected on the blot, however, confirmation and identification of the mutation with established methods such as sequencing or eventually hybridisation with oligonucleotides specific for the point mutation is required.

1 Fearon ER, Vogelstein B. A genetic model for colorectal tumorigenesis. Cell 1990;61:759-67.

2 Bos JL. Ras oncogenes in human cancer: A review. Cancer Res 1989;49:4682-9.

3 Orita M, Iwakana H, Kanazawa $H$, Hayashi K, Sekya $T$. Detection of polymorphisms of human DNA by gel electrophoresis as single strand conformation polymorphisms. Proc Natl Acad Sci USA 1989;86:2766-70.

4 Burmer GC, Rabinovitch PS, Loeb LA. Analysis of c-Kiras mutations in human colon carcinoma by cell sorting, polymerase chain reaction, and DNA sequencing. Cancer Res 1989;49:2141-6.

5 Verlaan-de Vries M, Bogaard ME, van den Elst H, van Boom JH, van der Eb AJ, Bos JL. A dot-blot screening procedure for mutated ras oncogenes using synthetic oligodeoxynucleotides. Gene 1986;50:313-20.

6 Murray V. Improved double-stranded DNA sequencin using the linear polymerase chain reaction. Nucleic Acids Res 1989;17:8889.

7 Lo YM, Patel P, Newton CR, Markham AF, Fleming KA, Wainscoat, JS. Direct haplotype determination by double ARMS: Specificity, sensitivity and genetic applications. Nucleic Acids Res 1991;19:3561-7. 